\title{
PLATAFORMA WEB PARA GERENCIAMENTO DE REQUERIMENTOS DISCENTES
}

DOI: 10.37702/2175-957X.COBENGE.2021.3599

Lucas Abismael da Rocha Soares - lars@poli.br

Universidade de Pernambuco

RUA 85 QD 62 BL 03 APT 102 S/N

53441-310 - PAULISTA - PE

Renata Machado de Miranda - rmm@poli.br

Universidade de Pernambuco

Rua Professor Augusto Lins e Silva 80

51030-030 - Recife - PE

VERUSCA SEVERO DE LIMA - verusca.severo@poli.br

UNIVERSIDADE DE PERNAMBUCO

RUA FRANCISCO LACERDA 90

50741-150 - RECIFE - PE

Resumo: Este trabalho tem como principal objetivo apresentar uma plataforma web, denominada de Requerimento Virtual, restrita ao departamento responsável pelos requerimentos discentes da Escola Politécnica de Pernambuco - POLI, Universidade de Pernambuco - UPE, viabilizando uma estrutura em que possam ser realizadas as tratativas das solicitações feitas pelos estudantes, centralizando diversas operações, tornando o processo mais ágil, organizado e transparente para as partes envolvidas, diminuindo, assim, a quantidade de etapas presenciais e documentos em papéis que protocolos deste caráter geralmente demandam. A plataforma desenvolvida neste trabalho permite o cadastramento de usuários (funcionários autorizados da universidade) com login e senha, para, posteriormente permitir que esse usuário faça a análise, gestão e finalização das solicitações requeridas pelos alunos, sempre com registro da data e do nome do funcionário responsável pela conclusão ou cancelamento daquela tratativa; todas as informações que transitam entre as etapas existentes na plataforma ficam armazenadas no banco de dados do MySQL. Além disso, a plataforma conta com uma ferramenta que permite armazenar os dados cadastrais de todos os requerentes (alunos da universidade) para possíveis consultas. Como base para a edição do código da plataforma foi utilizado o Sublime Text, e a linguagem de 
programação adotada foi o PHP através da estruturação em HTML, juntamente com aplicações em Javascript e estilização em CSS.

Palavras-chave: Plataforma web, Requerimentos discentes, MySQL, PHP. 


\section{PLATAFORMA WEB PARA GERENCIAMENTO DE REQUERIMENTOS DISCENTES}

\section{INTRODUÇÃO}

No início da década de 90, foi criado o primeiro site online, chamado "The Project", por Tim Berners-Lee, com o objetivo de compartilhar informações profissionais no Centro Europeu de Pesquisa Nuclear (CERN), sem precisar estar presente fisicamente no mesmo lugar com outros membros do centro, tendo como requisito a conexão no mesmo servidor (ESPINOSA; MIGUEL; GARCIA, 2021). Por definição, um site/website é uma página ou um conjunto de páginas da web organizadas e situadas em um servidor na rede, acessíveis através de um endereço online, também conhecido como domínio (JACKSI; ABASS, 2019).

Dentre os principais fatores que alavancaram o desenvolvimento de websites, podese citar: a necessidade por uma maior agilidade no acesso às informações, avanços na área de comunicação, constante aperfeiçoamento e desenvolvimento de tecnologias (VISCONTI, 2015). Atualmente existem diversos sites para áreas distintas, tais como em comunicação, vendas, jogos, saúde, finanças, entre outros. No âmbito escolar, é importante destacar que a utilização de websites vem sendo difundida cada vez mais nos últimos anos, principalmente, pela facilidade na utilização e possibilidade de armazenamento de informações de maneira organizada.

Tendo em vista algumas estruturas administrativas da Escola Politécnica de Pernambuco - POLI, Universidade de Pernambuco - UPE, é inevitável não pontuar aspectos a melhorar, sendo um deles a forma utilizada para administrar a solicitação dos requerimentos discentes (segunda chamada de exercício escolar, revisão de prova, declaração de matrícula, entre outros), que exige uma solicitação protocolada presencialmente envolvendo outros departamentos da universidade, juntamente com a entrega do termo de requisição e, em alguns casos, cópias de documentos, o que acaba gerando um grande volume de papel que só será utilizado para uma solicitação em específico; além de existir uma falta de comunicação entre as partes envolvidas, no que diz respeito ao andamento do processo de requerimento e sua respectiva conclusão, pois o departamento responsável não informa diretamente ao aluno sobre o fim da sua demanda, nem o aluno consegue acompanhar o andamento de forma remota, tendo que se deslocar presencialmente para saber acerca do progresso de sua solicitação, o que se torna um risco ao analisar o cenário da atualidade, onde é enfrentada uma pandemia que ameaça à saúde pública global, a pandemia do COVID-19 (do inglês, Coronavirus disease 2019).

Mediante os problemas citados, percebe-se a necessidade de desenvolvimento de uma plataforma virtual (website) que possibilite analisar e gerenciar as solicitações de requerimentos discentes da POLI/UPE, centralizando operações, otimizando e agilizando o procedimento, através da sua simplificação com a implementação do Requerimento Virtual.

O restante do trabalho encontra-se organizado como segue. A Seção 2 apresenta a metodologia, em que as ferramentas utilizadas para a elaboração desta plataforma são detalhadas. Em sequência, os resultados são apresentados na Seção 3, tornando possível associar todo conceito apresentado à implementação da prática proposta. E, por fim, a Seção 4 com as conclusões. 


\section{METODOLOGIA}

Para a implementação da plataforma proposta foi utilizado o Sublime Text como programa base para edição do código (SUBLIME TEXT, 2021). Enquanto que na construção do front-end (interface do usuário com o sistema) foram utilizadas as três principais linguagens responsáveis pelo desenvolvimento de código para a interface gráfica de um website, que são: o HTML; o Javascript; e o CSS intercalando à estrutura de estilização com o Bootstrap, que é um pacote de códigos para desenvolvimento de componentes de front-end.

No desenvolvimento do back-end (parte do programa que contém a implementação das regras do sistema) optou-se pelo uso da linguagem PHP (do inglês, Hypertext PreProcessor). Além disso, também foi utilizado o XAMPP, um pacote que inclui os principais servidores e aplicativos de código aberto do mercado (DVORSKI, 2007), dentre os quais foram utilizados o Apache, o MySQL e o phpMyAdmin, essas ferramentas, em conjunto, foram extremamente importantes para a criação da plataforma, uma vez que permitiram simular um servidor web localmente, gerando um excelente ambiente facilitador para o desenvolvimento, análise e testes, sem a necessidade de conexão com a internet.

\subsection{HTML, Javascript e CSS}

A linguagem HTML (do inglês, HyperText Markup Language), também conhecida como linguagem de marcação, é responsável por fazer a organização de diversos elementos na página, estruturando-os no código através de marcadores, que sinalizam o local da implementação desses elementos como cabeçalho, título, tabelas, imagens, entre outros (TORRES, 2018). Pode-se dividir o HTML na categoria de elementos bloco (cabeçalho, parágrafo, entre outros) e elementos em linha (formata as informações contidas nos elementos bloco), a partir desta estrutura é possível afirmar que uma página de site é composta por vários elementos bloco empilhados que seguem a hierarquia de informações do desenvolvedor. A versão adotada foi o HTML5, não somente por ser a versão mais recente e popular, mas também por tornar mais simples e rápida a navegação, ao permitir um melhor gerenciamento e a redução do tamanho de arquivos online, proporcionando uma otimização na experiência do usuário (SILVA, 2015).

O Javascript é uma linguagem de programação utilizada para o desenvolvimento de sistemas, serviços e aplicações de alta complexidade, pois permite controlar os elementos de uma página web. Mesmo sendo uma linguagem de programação, é importante ressaltar que o Javascript não cria aplicações independentes e na sua forma mais usual encontrase estruturado dentro de documentos HTML, possibilitando através dessa relação uma melhor interatividade para páginas web (NIXON, 2015). Dentre suas aplicações mais conhecidas, foram utilizadas neste trabalho: mostrar mensagens através de janelas de aviso e confirmação, fazer verificações por meio da validação de formulários e alterar as informações conforme as interações do usuário nas páginas do site.

Denominado como linguagem de estilos, o CSS (do inglês, Cascading Style Sheets), que está em sua na terceira versão (CSS3), é utilizado para definir cores, tamanhos, alinhamentos, fontes, posicionamentos ou qualquer outro elemento estético de uma página web (SILVA, 2015). Serve para dar estilo de forma prática e organizada ao que foi elaborado no HTML, personalizando dessa forma o conteúdo visível ao usuário (ALVES, 2017). Em suma, no desenvolvimento deste trabalho, o CSS foi inserido através de um arquivo de estilo que permitiu referenciar os elementos desejados do HTML evitando assim repetir informações desnecessárias diretamente na estrutura do código. 


\subsection{PHP}

A linguagem de programação PHP é uma das principais e mais adequadas para o desenvolvimento web, pois pode ser inserida dentro do HTML, trabalhando de forma declarativa, eficiente e flexível, possibilitando a criação de interações cada vez mais complexas (TRATOE; MACINTYRE, 2020), em decorrência a isto foi a linguagem escolhida para este trabalho.

O PHP é mais utilizado para aplicações que envolvam a comunicação do lado do servidor (back-end) (ALVES, 2017), desempenhando assim algumas funções como coleta, armazenamento, alteração e exclusão da base de dados, gerenciamento de arquivos de servidor, entre outras.

\subsection{Apache, MySQL e phpMyAdmin}

Embora o Apache seja denominado como um servidor web de código aberto, ele não é um servidor físico, trata-se de um software multiplataforma executado em um servidor (NIXON, 2015). Além disso, o Apache é funcional e flexível devido à sua arquitetura ser estruturada em módulos. A comunicação entre cliente e servidor ocorre por meio do protocolo HTTP (do inglês, Hypertext Transfer Protocol) que é um protocolo base de comunicação de dados da web, e por ser compatível com esse protocolo, o Apache é o encarregado de facilitar e garantir o sucesso dessa comunicação, estabelecendo, neste trabalho, a conexão entre o servidor e o navegador do website, enquanto gerencia a retirada e a entrega de arquivos entre eles (ALVES, 2017).

O MySQL é um sistema de gerenciamento de banco de dados relacionais, RDBMS (do inglês, Relational Database Management System), de código aberto com linguagem de consulta estruturada, SQL (do inglês, Structure Query Language), baseado no modelo de relação cliente-servidor, que armazena e gerencia os dados de forma organizada em tabelas (NIXON, 2015; ORACLE, 2021). Neste trabalho, a sua utilização possibilitou acessar e manipular informações específicas no banco de dados compondo o back-end com o Apache, ambos ativados e conectados pela ferramenta XAMPP, que também é responsável por interligar esse sistema ao phpMyAdmin.

O phpMyAdmin é uma aplicação de código aberto e uso livre desenvolvido em PHP responsável por ser o administrador de banco de dados em MySQL (PHPMYADMIN, 2021). Dentre as suas principais funções é válido destacar as essenciais para o desenvolvimento deste trabalho que foram: inserção, acesso, exclusão e gerenciamento do conteúdo armazenado no banco de dados em MySQL; carregamento de tabelas; administração dos servidores na interface do navegador e a execução de buscas específicas dentro do banco de dados.

\section{RESULTADOS}

Esta seção apresenta a plataforma web desenvolvida. Primeiramente, para auxiliar a compreensão da dinâmica estabelecida neste trabalho, é apresentado na Figura 10 fluxograma funcional, ilustrando as interações das páginas do site (front-end) com as suas respectivas tabelas localizadas no banco de dados (back-end), que são responsáveis por armazenar e fornecer dados a todas as páginas do site.

Como poder ser visto na Figura 1, a página de Login está conectada à página de Cadastro, ambas interligadas à tabela usuários (responsável por armazenar as informações dos usuários, permitindo, assim, a validação do login e armazenamento de dados enviados 
na parte do cadastro). A página de Login conecta-se também à página Inicial, que não se conecta diretamente a nenhuma tabela, entretanto desempenha um importante papel, visto que é o ponto central para as outras páginas do site.

A tabela dados contém as solicitações dos discentes (informações que foram carregadas manualmente a título de simulação da plataforma web) que são expostas na página de Requerimentos Solicitados, em seguida, essas informações podem migrar para a tabela enviados (que preenche a página de Requerimentos em Andamento) ou para a tabela lixeira (que preenche a página de Requerimentos Excluídos), estas duas opções dependem da interatividade do usuário e serão expostas adiante.

A tabela enviados, por sua vez, é responsável por preencher a página de Requerimentos em Andamento, após esse preenchimento, esses dados podem migrar para a tabela terminados (que preenche a página de Requerimentos Finalizados) ou para a tabela lixeira (que preenche a página de Requerimentos Excluídos), estas duas opções também dependem da interatividade do usuário e serão expostas adiante.

A tabela terminados fornece os dados para a página de Requerimentos Finalizados, em seguida, esses dados seguem para a página de Requerimentos Finalizados Concluídos, e são armazenados na tabela concluídos, que podem ser acessados pela página de Requerimentos Finalizados - Concluídos.

A tabela lixeira armazena os dados migrados da tabela dados e tabela enviados, expondo essas informações na página de Requerimentos Excluídos.

A página de Cadastro dos Alunos está conectada à página de Detalhe do Cadastro e ambas coletam informações da tabela estudantes (responsável por armazenar as informações dos discentes, que foram carregadas manualmente a título de simulação da plataforma web).

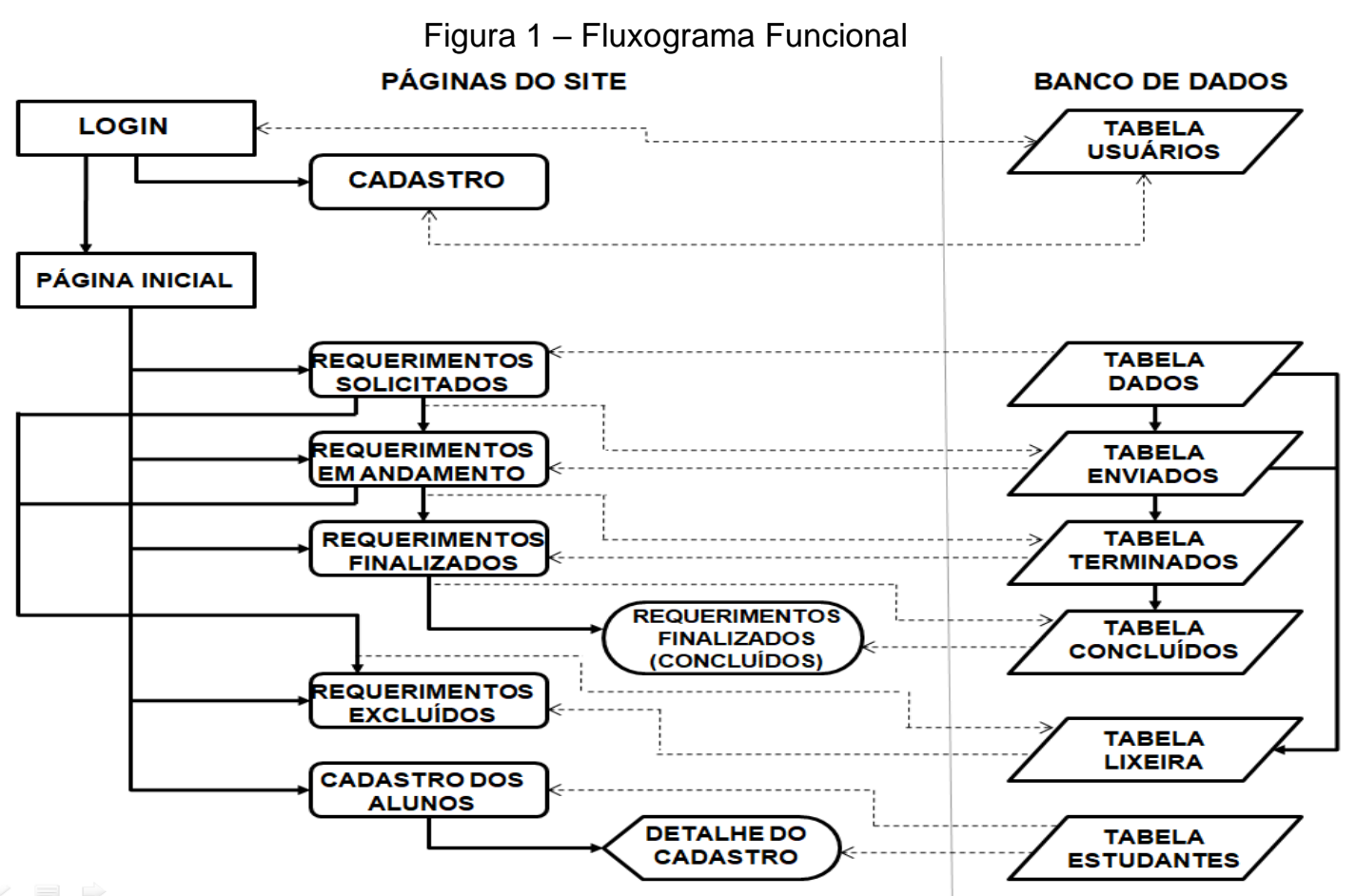

Fonte: Autoria própria.

Ao efetuar o acesso ao website, o usuário é direcionado à página de Login que libera o acesso mediante ao preenchimento de e-mail e senha corretos, como pode ser observado 
na Figura 2(a). Na página de Cadastro, apresentada na Figura 2(b), é possível efetuar o cadastramento de novos usuários, mediante o preenchimento de alguns dados. Essas duas primeiras páginas estão interligadas com a tabela usuários do banco de dados, que, por meio de comparações, verifica se as informações no login são válidas e impedem que dados, tais como e-mail e CPF, sejam reutilizados no cadastramento de novos usuários.

Figura 2 - Páginas de Login e Cadastro.

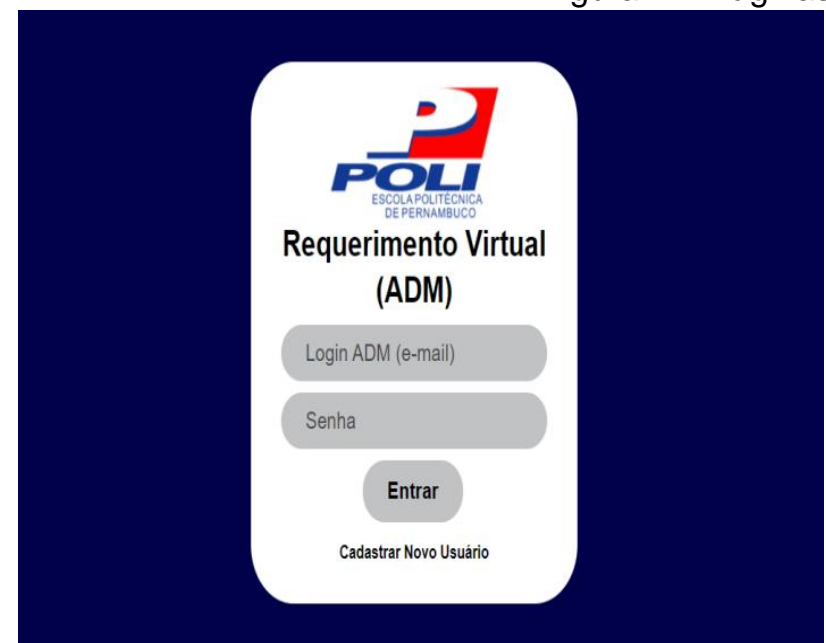

(a) Página de Login

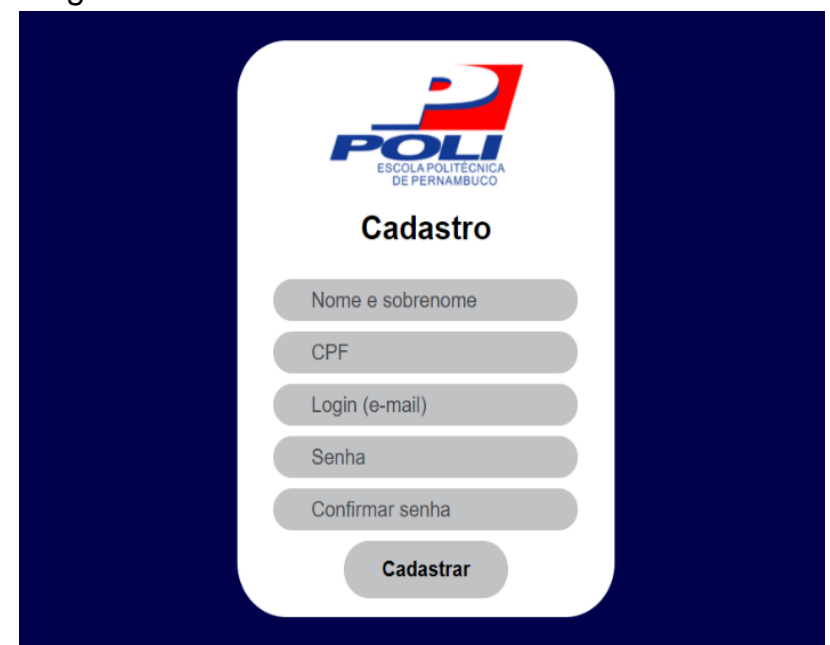

(b) Página de Cadastro

Fonte: Autoria própria.

Além disso, o usuário que tentar acessar qualquer página interna do site, sem efetuar o login, não obterá êxito, pois cada usuário ao ser cadastrado recebe uma identificação única chamada de id_usuario, armazenada na tabela usuários, conforme ilustra a Figura 3, que permite saber se a sessão foi iniciada de forma adequada, impedindo que o sistema seja burlado. Outra ferramenta de segurança utilizada foi a criptografia da senha criada no cadastro, desenvolvida através do algoritmo md5 que converte a senha desejada em uma função hash de 32 caracteres e, somente após isso, registra a senha criptografada na tabela usuários, evitando a exposição da senha e, consequentemente, protegendo todas as atividades do usuário dentro da plataforma.

Figura 3 - Tabela Usuários.

\begin{tabular}{rlllll}
\hline id_usuario & $\Delta 1$ & nome & cpf & email & senha \\
\hline 6 & Lucas Abismael & 10976423378 lars@poli.br & e10adc3949ba59abbe56e057f20f883e \\
7 & Rejane Vieira & 14567899448 rvar@poli.br & 202cb962ac59075b964b07152d234b70
\end{tabular}

Fonte: Autoria própria.

Ao iniciar uma sessão, o funcionário da instituição é direcionado para a página Inicial, representada na Figura 4, onde tem acesso às estruturas funcionais do site. Na página em questão é mostrado o nome do usuário, isso é possível graças ao id_usuario que permite identificar o nome do responsável pelo acesso.

Na página Inicial constam as seções de Requerimentos (Solicitados, em Andamento, Finalizados, Concluídos e Excluídos) e Cadastro de Alunos. Todas as seções de requerimentos funcionam em esquema sequencial com término na etapa de Requerimentos Finalizados (Concluídos) ou em Requerimentos Excluídos, representando respectivamente, 
o êxito ou não êxito do processo. Todas as conexões estão num constante fluxo de troca de informações com as suas respectivas tabelas no banco de dados.

Figura 4 - Página Inicial.

Seja bem-vindo(a), Lucas Abismael
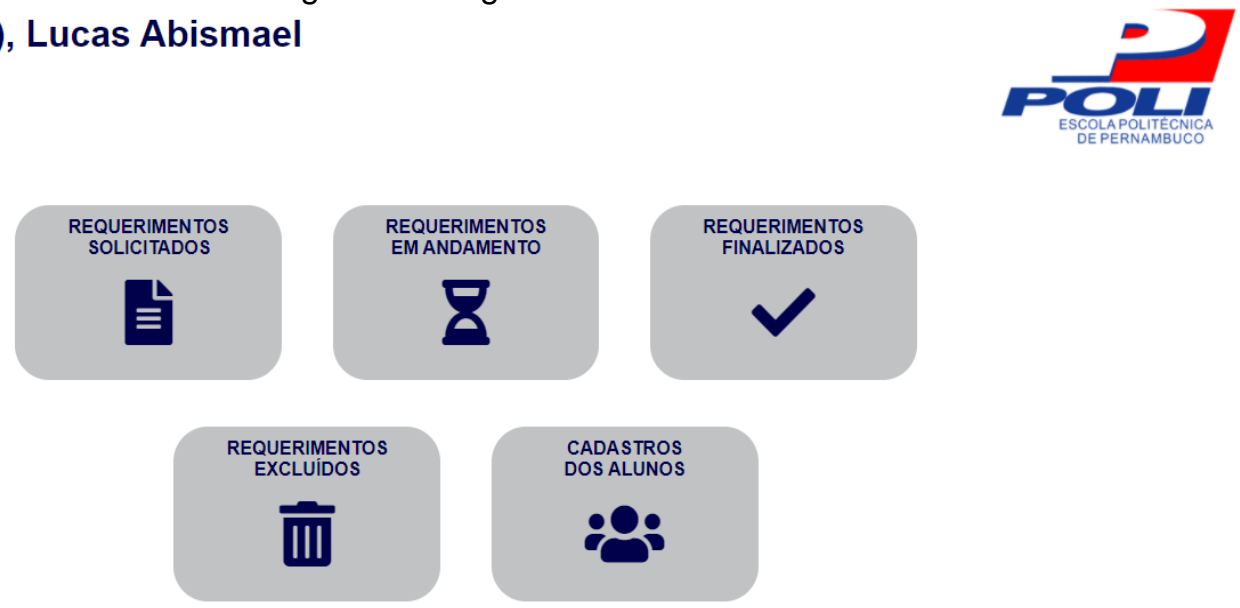

4)

Fonte: Autoria própria.

Para parâmetros de explicação, todas as seções de requerimentos citadas no parágrafo anterior serão mostradas a seguir. A Figura 5 ilustra a página de Requerimentos Solicitados, as informações expostas nesta seção são provenientes da tabela dados do banco de dados, onde foram inseridas manualmente as solicitações dos alunos com a finalidade de criar uma estrutura de simulação propícia para demonstrar o funcionamento do site.

Figura 5 - Página de Requerimentos Solicitados.
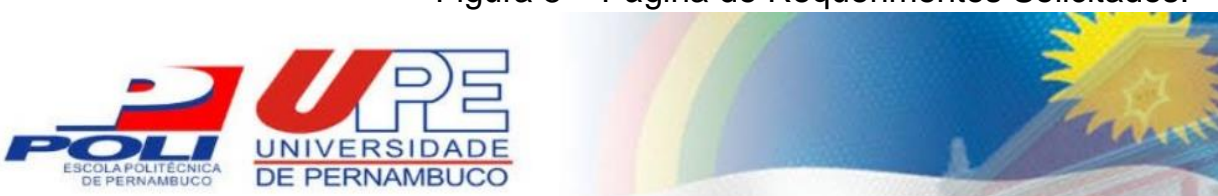

\section{Requerimentos Solicitados}

$\leftarrow$

\begin{tabular}{|c|c|c|c|c|c|c|c|c|c|}
\hline $\begin{array}{l}\text { Número do } \\
\text { Protocolo }\end{array}$ & $\begin{array}{l}\text { Nome do } \\
\text { Solicitante }\end{array}$ & $\begin{array}{l}\text { CPF do } \\
\text { Solicitante }\end{array}$ & $\begin{array}{c}\text { Data da } \\
\text { Solicitação }\end{array}$ & $\begin{array}{c}\text { Tipo de } \\
\text { Requerimento }\end{array}$ & Anexo & $\begin{array}{l}\text { Valor } \\
\text { (R\$) }\end{array}$ & Observações & Confirmar & r Excluir \\
\hline 116 & $\begin{array}{l}\text { Maria Helena de } \\
\text { Lima }\end{array}$ & 08655344548 & $\begin{array}{c}02 / 04 / 2021 \\
16: 51: 22\end{array}$ & $\begin{array}{l}\text { Trancamento de } \\
\text { Matrícula }\end{array}$ & Anexo & 70,00 & O comprovante de transferência está anexado. & & X \\
\hline 117 & $\begin{array}{c}\text { João Luiz } \\
\text { Cândido da Silva }\end{array}$ & 12879444488 & $\begin{array}{c}06 / 04 / 2021 \\
10: 36: 52\end{array}$ & $\begin{array}{l}\text { Colação de Grau } \\
\text { Especial }\end{array}$ & Anexo & 60,00 & $\begin{array}{l}\text { Documentação necessária e comprovante de depósito bancário } \\
\text { seguem em anexo. }\end{array}$ & & $\mathbf{x}$ \\
\hline 125 & $\begin{array}{c}\text { Renata Machado } \\
\text { de Miranda }\end{array}$ & 10456688338 & $\begin{array}{l}07 / 04 / 2021 \\
14: 42: 23\end{array}$ & Declaração de Matrícula & Anexo & 9,00 & $\begin{array}{l}\text { Comprovante de transferência bancária anexado em pdf à } \\
\text { solicitação. }\end{array}$ & & $\mathbf{x}$ \\
\hline 126 & $\begin{array}{l}\text { Matheus Souza } \\
\text { de Melo }\end{array}$ & 17699078068 & $\begin{array}{l}08 / 04 / 2021 \\
18: 42: 23\end{array}$ & $\begin{array}{l}\text { Segunda Chamada de } \\
\text { Exercicio Escolar }\end{array}$ & $\underline{\text { Anexo }}$ & 18,00 & $\begin{array}{l}2^{\circ} \text { Chamada do } 1^{\circ} E E \text { de Antenas do dia 07/04/2021, Turma AE do } \\
\text { Prof. Alcione Alves. Atestado médico e pagamento anexados. }\end{array}$ & & $\mathbf{x}$ \\
\hline 131 & $\begin{array}{l}\text { Sandra Oliveira } \\
\text { dos Santos }\end{array}$ & 12598976838 & $\begin{array}{c}12 / 04 / 2021 \\
15: 56: 13\end{array}$ & $\begin{array}{c}\text { Autorização para cursar } \\
\text { Disciplina Isolada }\end{array}$ & $\underline{\text { Anexo }}$ & 58,00 & Em anexo, pagamento e documentação. & & $\mathbf{Y}$ \\
\hline
\end{tabular}

Fonte: Autoria própria.

Como é possível ver na Figura 5, cada requerimento solicitado possui as seguintes informações: número do protocolo e data da solicitação, nome e CPF do solicitante, tipo do 
requerimento, anexo, valor e observação. O funcionário da instituição antes de fazer a tratativa da solicitação deve verificar na parte de anexo o pagamento e a documentação; estando de acordo, basta prosseguir com a confirmação, caso contrário, deve proceder com a exclusão. Ao efetuar qualquer uma das duas ações, automaticamente aparecerá uma mensagem para validação que foi desenvolvida em Javascript, como pode ser observada na Figura 6, diminuindo as chances de um eventual erro, tendo em vista a necessidade de confirmar novamente. É necessário pontuar que essas mensagens de validação estão presentes nas principais tomadas de decisões dentro do site.

Figura 6 - Mensagens de Validação.

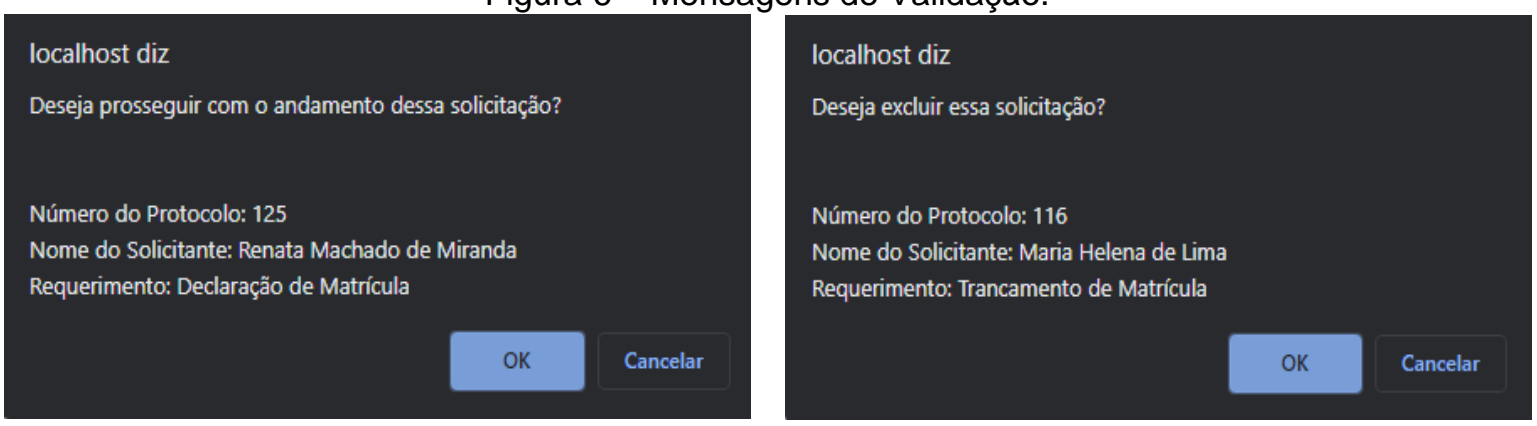

Fonte: Autoria própria.

Estando a solicitação na página de Requerimentos em Andamento, significa dizer que foi confirmada na seção anterior (Requerimentos Solicitados), logo, as informações foram transferidas no banco de dados da tabela dados para a tabela enviados, sendo esta última, a responsável por fornecer as informações mostradas na seção da Figura 7 .

Neste momento, o usuário deve solucionar a demanda do solicitante (providenciar a documentação/autorizar a solicitação) e com um resultado definido deve optar entre a confirmação (finalização do processo) ou exclusão.

Figura 7 - Página de Requerimentos em Andamento.

\section{Requerimentos em Andamento}

$\leftarrow$

\begin{tabular}{|c|c|c|c|c|c|c|c|c|c|}
\hline $\begin{array}{l}\text { Número do } \\
\text { Protocolo }\end{array}$ & $\begin{array}{l}\text { Nome do } \\
\text { Solicitante }\end{array}$ & $\begin{array}{c}\text { CPF do } \\
\text { Solicitante }\end{array}$ & $\begin{array}{c}\text { Data da } \\
\text { Solicitação }\end{array}$ & $\begin{array}{c}\text { Tipo de } \\
\text { Requerimento }\end{array}$ & Anexo & $\begin{array}{l}\text { Valor } \\
\text { (R\$) }\end{array}$ & Observações & Confirmar & Excluir \\
\hline 117 & $\begin{array}{c}\text { João Luiz } \\
\text { Cândido da Silva }\end{array}$ & 12879444488 & $\begin{array}{l}06 / 04 / 2021 \\
10: 36: 52\end{array}$ & $\begin{array}{l}\text { Colação de Grau } \\
\text { Especial }\end{array}$ & Anexo & 60,00 & $\begin{array}{l}\text { Documentação necessária e comprovante de depósito bancário } \\
\text { seguem em anexo. }\end{array}$ & ( & $x$ \\
\hline 125 & $\begin{array}{c}\text { Renata Machado } \\
\text { de Miranda }\end{array}$ & 10456688338 & $\begin{array}{l}07 / 04 / 2021 \\
14: 42: 23\end{array}$ & Declaração de Matrícula & Anexo & 9,00 & $\begin{array}{l}\text { Comprovante de transferência bancária anexado em pdf à } \\
\text { solicitaçẫo. }\end{array}$ & ( & $\mathbf{x}$ \\
\hline 126 & $\begin{array}{l}\text { Matheus Souza } \\
\text { de Melo }\end{array}$ & 17699078068 & $\begin{array}{l}08 / 04 / 2021 \\
18: 42: 23\end{array}$ & $\begin{array}{c}\text { Segunda Chamada de } \\
\text { Exercicio Escolar }\end{array}$ & Anexo & 18,00 & $\begin{array}{l}2^{\circ} \mathrm{Chamada} \text { do } 1^{0} \mathrm{EEE} \text { de Antenas do dia } 07 / 04 / 2021 \text {, Turma AE do } \\
\text { Prof. Alcione Alves. Atestado médico e pagamento anexados. }\end{array}$ & ( & $x$ \\
\hline 131 & $\begin{array}{c}\text { Sandra Oliveira } \\
\text { dos Santos }\end{array}$ & 12598976838 & $\begin{array}{l}\text { 12/04/2021 } \\
15: 56: 13\end{array}$ & $\begin{array}{l}\text { Autorização para cursar } \\
\text { Disciplina Isolada }\end{array}$ & Anexo & 58,00 & Em anexo, pagamento e documentação. & ( & $x$ \\
\hline
\end{tabular}

Fonte: Autoria própria.

Supondo que a solicitação seja confirmada, ela segue para a página de Requerimentos Finalizados, ou seja, as informações são transferidas no banco de dados da tabela enviados para a tabela terminados. Nesta nova seção, como pode ser observado na Figura 8, é acrescentado o nome do responsável (através da relação com o id_usuario) e a data, estas duas informações são muito importantes, pois através desse registro tornase possível identificar quem finalizou o processo e quando isso foi realizado. 
Figura 8 - Página de Requerimentos Finalizados.

\section{Requerimentos Finalizados}

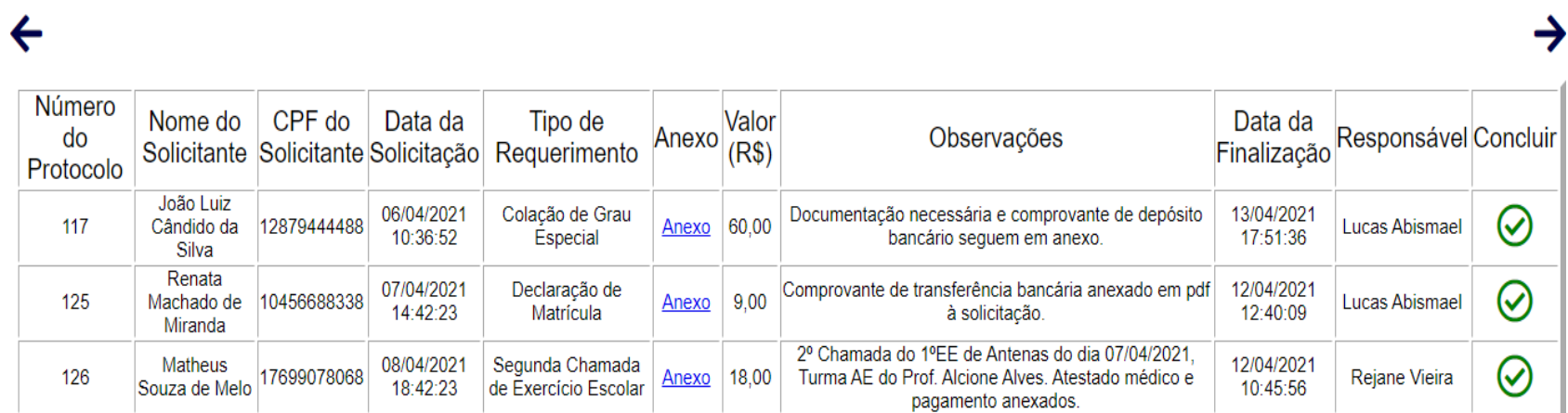

Fonte: Autoria própria.

Com a solicitação finalizada, a última coisa a ser feita é confirmar a conclusão do processo, fazendo com que a solicitação seja exposta na página de Requerimentos Finalizados - Concluídos, o que significa afirmar que as informações foram transferidas no banco de dados da tabela terminados para serem arquivadas na tabela concluídos. Nesta última seção da sequência, como pode ser visto na Figura 9, é inserida uma nova coluna que identifica o funcionário responsável pela conclusão do processo (arquivamento), seguindo o mesmo princípio do id_usuario citado anteriormente. Além disso, é possível observar que o mesmo processo poderá ter dois responsáveis diferentes, um pela finalização e o outro pela conclusão. Um exemplo prático é o caso da segunda solicitação da Figura 9, em que um usuário finalizou o processo, providenciando a declaração de matrícula e está apenas no aguardo da aluna retirar a sua documentação; após a confirmação da entrega do documento diretamente para a estudante, um segundo usuário também autorizado, concluiu o processo arquivando-o, tendo em vista que recebeu a confirmação da entrega antes do primeiro usuário, agilizando as respostas dentro do site.

Figura 9 - Página de Requerimentos Finalizados - Concluídos.

\section{Requerimentos Finalizados - Concluídos}

$\leftarrow$

\begin{tabular}{|c|c|c|c|c|c|c|c|c|c|c|}
\hline $\begin{array}{c}\text { Número } \\
\text { do } \\
\text { Protocolo }\end{array}$ & $\begin{array}{l}\text { Nome do } \\
\text { Solicitante }\end{array}$ & $\begin{array}{l}\text { CPF do } \\
\text { Solicitante }\end{array}$ & $\begin{array}{l}\text { Data da } \\
\text { Solicitação }\end{array}$ & $\begin{array}{l}\text { Tipo de } \\
\text { Requerimento }\end{array}$ & Anexo & $\begin{array}{l}\text { Valor } \\
(\mathrm{R} \$)\end{array}$ & Observações & $\begin{array}{c}\text { Data da } \\
\text { Finalização }\end{array}$ & Responsável & $\begin{array}{l}\text { Responsável } \\
\text { (conclusão) }\end{array}$ \\
\hline 117 & $\begin{array}{l}\text { João Luiz } \\
\text { Cândido da } \\
\text { Silva }\end{array}$ & 12879444488 & $\begin{array}{c}06 / 04 / 2021 \\
10: 36: 52\end{array}$ & $\begin{array}{l}\text { Colação de Grau } \\
\text { Especial }\end{array}$ & Anexo & 60,00 & $\begin{array}{l}\text { Documentação necessária e comprovante de } \\
\text { depósito bancário seguem em anexo. }\end{array}$ & $\begin{array}{c}14 / 04 / 2021 \\
11: 21: 39\end{array}$ & Lucas Abismael & Lucas Abismael \\
\hline 125 & $\begin{array}{l}\text { Renata } \\
\text { Machado de } \\
\text { Miranda }\end{array}$ & 10456688338 & $\begin{array}{c}07 / 04 / 2021 \\
14: 42: 23\end{array}$ & $\begin{array}{l}\text { Declaração de } \\
\text { Matrícula }\end{array}$ & Anexo & 9,00 & $\begin{array}{c}\text { Comprovante de transferência bancária anexado em } \\
\text { pdf à solicitação. }\end{array}$ & $\begin{array}{c}13 / 04 / 2021 \\
17: 05: 46\end{array}$ & Lucas Abismael & Rejane Vieira \\
\hline 126 & $\begin{array}{l}\text { Matheus } \\
\text { Souza de } \\
\text { Melo }\end{array}$ & 17699078068 & $\begin{array}{c}08 / 04 / 2021 \\
18: 42: 23\end{array}$ & $\begin{array}{l}\text { Segunda Chamada } \\
\text { de Exercício } \\
\text { Escolar }\end{array}$ & Anexo & 18,00 & $\begin{array}{l}2^{\circ} \text { Chamada do } 1^{\circ} \mathrm{EE} \text { de Antenas do dia } 07 / 04 / 2021, \\
\text { Turma AE do Prof. Alcione Alves. Atestado médico e } \\
\text { pagamento anexados. }\end{array}$ & $\begin{array}{c}12 / 04 / 2021 \\
10: 46: 23\end{array}$ & Rejane Vieira & Rejane Vieira \\
\hline
\end{tabular}

Fonte: Autoria própria.

Se na etapa de Requerimentos Solicitados ou em Andamento a solicitação for excluída, seguirá o mesmo princípio de registrar o responsável, nesse caso pela exclusão, além do dia e horário, transferindo as informações no banco de dados da tabela dados/tabela enviados para a tabela lixeira, obtendo como resultado os dados expostos na página de Requerimentos Excluídos apresentada na Figura 10. 
Figura 10 - Página de Requerimentos Excluídos.

\section{Requerimentos Excluídos}

$\leftarrow$

\begin{tabular}{|c|c|c|c|c|c|c|c|c|c|}
\hline $\begin{array}{c}\text { Número do } \\
\text { Protocolo }\end{array}$ & $\begin{array}{c}\text { Nome do } \\
\text { Solicitante }\end{array}$ & $\begin{array}{c}\text { CPF do } \\
\text { Solicitante }\end{array}$ & $\begin{array}{c}\text { Data da } \\
\text { Solicitação }\end{array}$ & Tipo de Requerimento Anexo & $\begin{array}{c}\text { Valor } \\
\text { (RS) }\end{array}$ & Observações & $\begin{array}{c}\text { Data de } \\
\text { Exclusão }\end{array}$ & Responsável \\
\hline 116 & $\begin{array}{c}\text { Maria Helena de } \\
\text { Lima }\end{array}$ & 08655344548 & $\begin{array}{c}02 / 104 / 2021 \\
16: 51: 22\end{array}$ & Trancamento de Matrícula & Anexo & 70,00 & $\begin{array}{c}\text { O comprovante de transferência } \\
\text { está anexado. }\end{array}$ & $\begin{array}{c}\text { 05/04/2021 } \\
10: 35: 18\end{array}$ & Lucas Abismael \\
\hline 131 & $\begin{array}{c}\text { Sandra Oliveira dos } \\
\text { Santos }\end{array}$ & 12598976838 & $\begin{array}{c}12 / 04 / 2021 \\
15: 56: 13\end{array}$ & $\begin{array}{c}\text { Autorização para cursar } \\
\text { Disciplina Isolada }\end{array}$ & Anexo & 58,00 & $\begin{array}{c}\text { Em anexo, pagamento e } \\
\text { documentaçãa. }\end{array}$ & $\begin{array}{c}14 / 04 / 2021 \\
15: 46: 05\end{array}$ & Rejane Vieira \\
\hline
\end{tabular}

Fonte: Autoria própria.

A página de Cadastros de Alunos mostrada na Figura 11, foi desenvolvida para facilitar uma eventual comunicação entre os usuários com os estudantes cadastrados. Consiste, basicamente, numa tabela organizada em ordem alfabética com nome, CPF, curso, telefone e e-mail do aluno. Ao clicar na opção de detalhes, o usuário consegue visualizar de forma isolada a linha selecionada da tabela. É válido ressaltar, ainda, que o conteúdo desta seção é proveniente da tabela estudantes do banco de dados, onde foram inseridas manualmente as informações com a finalidade de criar uma estrutura de simulação propícia para demonstrar o funcionamento desta página do site.

Figura 11 -Página de Cadastros dos Alunos.

\section{Cadastros dos Alunos}

$\leftarrow$

\begin{tabular}{|c|c|c|c|c|c|}
\hline Nome & CPF & Curso & Telefone & E-mail & Detalhes \\
\hline João Luiz Cândido da Silva & $128.794 .444-88$ & Engenharia de Controle e Automação & (81)999433565 & joao.luiz_cs@gmail.com & \\
\hline Maria Helena c & 086.553.445-48 & Engenharia Mecânica & (81)998765567 & maria.hlima28@gma & \\
\hline Matheus Sol & 17 & Engenharia Elé & \multicolumn{2}{|c|}{ (81)988343503 matheus.souza.melo@hotmail.com } & \\
\hline a Macha & 104.566 .88 & Engenharia Elétrica de & (81)99 & renata.miranda@ & \\
\hline Sandra Oliveira dos Santos & $125.989 .768-38$ & Engenharia Civil & (81)979945567 & sandra.o.santos@hotmail.com & \\
\hline
\end{tabular}

Fonte: Autoria própria.

\section{CONCLUSÕES}

É notório que há a necessidade de otimizar o processo de administração dos requerimentos solicitados por parte dos discentes da Escola Politécnica de Pernambuco POLI, Universidade de Pernambuco - UPE, pois exige um processo protocolado presencialmente envolvendo diversos departamentos da universidade. Além disso, a ausência de comunicação direta entre o discente e o setor administrativo encarregado da tratativa de requerimentos, gera uma barreira desnecessária por inexistir uma forma remota de solicitar requerimentos e acompanhar todo o andamento da solicitação, ainda mais no atual período de pandemia, em que uma das medidas adotada para se proteger e frear a pandemia é o isolamento social.

Do início ao fim de um processo de requerimento é gerada uma grande quantidade de papéis (termo de requisição, comprovante de pagamento e, em alguns casos, cópia de documentos) que só são utilizados uma única vez, e que no término do processo, serão arquivados na universidade ocupando um espaço físico desnecessário. 
Diante do cenário exposto, o objetivo deste trabalho é o desenvolvimento de uma plataforma web restrita ao departamento responsável pela administração de requerimentos discentes da POLI/UPE, com a funcionalidade de tratar as solicitações feitas pelos estudantes.

Por meio desse trabalho, espera-se contribuir com o processo de gerenciamento das solicitações de requerimentos da POLI/UPE, centralizando operações, otimizando e agilizando os procedimentos, além de reduzir a quantidade de papéis utilizados (visto que todos os documentos são digitais), tudo isso através da sua simplificação com a implementação do website de Requerimento Virtual.

Como trabalhos futuros pode-se destacar a conexão do website proposto com um aplicativo para smartphone, em que o aluno possa solicitar e acompanhar seus requerimentos, levando também para o formato digital os documentos que são requisitados. Este compartilhamento de informações entre universidade e aluno, ocorrerá pelo banco de dados, uma vez que a solicitação do requerente, ao entrar no sistema, permanece em uma das tabelas deste banco, podendo ser facilmente recuperada e associada a um status de progresso. É importante justificar que a etapa para recuperação de senha não foi integrada neste protótipo, pois necessita da aquisição de um serviço de hospedagem pago, que dentre diversas funções engloba o envio de mensagem para o e-mail do usuário com o intuito de validar a recuperação da senha; além disso, com a posse desse serviço, também é aplicável o bloqueio de acesso ao site por computadores que não sejam os autorizados pela universidade.

\section{REFERÊNCIAS}

ALVES, William Pereira. Construindo uma Aplicação Web Completa com PHP e MySQL. 1. ed. São Paulo: Novatec Editora, 2017. 520 p. ISBN: 978-85-7522-536-3.

\section{DVORSKI, Dailibor D. INSALLING, CONFIGURING, AND DEVELOPING WITH XAMPP, Ontario, p. 1-10, Mar. 2007. Disponível em: http://dalibor.dvorski.net/downloads/docs/installingconfiguringdevelopingwithxampp.pdf. Acesso em: 06 mar. 2021.}

ESPINOSA, P.; MIGUEL, A.; GARCIA, F. Tim Berners-Lee frente a los dueños de Internet en la era de la sobre información. Estudios sobre el Mensaje Periodístico, Madrid, v. 27, n. 1, p. 365-374, Jan. 2021.

JACKSI, K.; ABASS, S. Development History Of The World Wide Web. International Journal of Scientific \& Technology Research (IJSTR), v. 8, n. 9, p. 75-79, Set. 2019.

NIXON, Robin. Learning PHP, MySQL, Javascript, CSS \& HTML5: A Step-By-Step Guide to Creating Dynamic Websites. 3. ed. California: O'Reilly Media, 2014. 700 p. ISBN: 978-1491-94946-7.

ORACLE. MySQL Database Service. Disponível em: https://www.oracle.com/mysql/. Acesso em: 13 mar. 2021. 
PHPMYADMIN. Bringing MySQL to the Web. Disponível em: https://www.phpmyadmin.net/. Acesso em: 13 mar. 2021.

SILVA, Maurício Samy. Fundamento de HTML5 e CSS3. 1. ed. São Paulo: Novatec Editora, 2015. 304 p. ISBN: 978-85-7522-438-0.

SUBLIME TEXT. A sophisticated text editor for code, markup and prose. Disponível em: https://www.sublimetext.com/. Acesso em: 05 mar. 2021.

TORRES, V. M. HTML e seus Componentes. Revista Ada Lovelace, [s.I.], v. 2, p. 99-101, 2018.

Disponível

em:

http://anais.unievangelica.edu.br/index.php/adalovelace/article/view/4652. Acesso em: 06 abr. 2021.

TRATOE, Kevin; MACINTYRE, Peter. Programming PHP: Creating Dynamic Pages. 4. ed. California: O’Reilly Media, 2020. 540 p. ISBN: 978-1-492-05413-9.

VISCONTI, Gabriel Braga. Sistema de Gerenciamento de Equipes e Tarefas. 2015. Trabalho de Conclusão de Curso (Bacharelado em Ciência da Computação) - Instituto de Informática, Universidade Federal do Rio Grande do Sul, Porto Alegre, 2015.

\title{
WEB PLATFORM FOR MANAGING STUDENT REQUIREMENTS
}

\begin{abstract}
This project aims to present a web platform, named Virtual Requirement, restricted to the department responsible for the student requirements of the Polytechnic School of Pernambuco - POLI, University of Pernambuco - UPE, as a way to enable a structure where the requests made can be dealt with by students, centralizing several operations, making the process more agile, organized and transparent for the parties involved, thus reducing the number of face-to-face steps and paper documents that protocols of this character usually demand. The platform developed in this project allows the registration of users (authorized employees of the University) with login and password, to subsequently allow this user to analyze, manage and finalize the requests required by students, always with the date and name of the employee responsible for completing or canceling that deal; all information that moves between the steps on the platform is stored in the MySQL database. In addition, the platform has a tool that allows store the registration data of all applicants (University students) for possible queries. As a basis for editing the platform code, Sublime Text was used and the programming language adopted was PHP through the structuring in HTML, together with applications in Javascript and stylization in CSS.
\end{abstract}

Keywords: Web platform, Student requirements, MySQL, PHP. 